\title{
Seismotectonic research in China
}

\section{*State Seismological Bureau, Beijing 100036}

The China continent is an area with intense neotectonic movement and high seismicity, in which the occurrences of many large earthquakes are closely related to certain tectonic environment. This review briefly introduces recent advancements in the field of seismotectonics, including characteristics of seismicity, tectonic framework for large earthquakes, active faults associated with earthquakes, recent crustal movement and the division of seismic regions and belts.

\section{Introduction}

The China continent lies on the eastern edge of the Eurasia Plate. The wide-spread Cenozoic crustal deformation and neotectonic movement were resulted from interaction among the collision between the India Plate and the Eurasia Plate and the uplift of the Tibetan plateau, the subduction of the Western Pacific Plate beneath the Asia Plate, the collision between the Philippines Plate and the Asia Plate near Taiwan, and the deep tectonic and thermal activity underneath the Chinese continent. Frequently occurred strong earth- quakes are manifestation of the recent tectonic activity over most part of China.

\section{Seismicity}

China is a country with long and abundant historical earthquake records. The duration of which can be traced back for 3828 years since the first record of the $1831 \mathrm{BC}$ earthquake. However, the temporal and spacial distribution of historical earthquake records are quite different. The relative systematic and complete records of strong earthquakes are mainly distributed in North China with the duration of recent 500 years. According to " Earthquake Catalogue in China" (Gu Gongxu et al., 1983) and historical earthquake data of the adjacent areas of China, there were only 36 records for strong earthquake with $\mathrm{M} \geq 7.7$, and the spacial distribution of which concentrated on several regions such as Qinghai-Tibet plateau, Pamir, Tianshan, Altai, North China and Taiwan (Figure 1).

The activity of strong earthquakes in China shows the characteristics of episodic activity followed by a period of seismic quiescence. K. Moji (1985) suggested that the activity of major global seismic belts in this century had the similar characteristics with a short quiescent interval about 20 years. The long time records of historical earthquakes from China also indicated a long fluctuating process

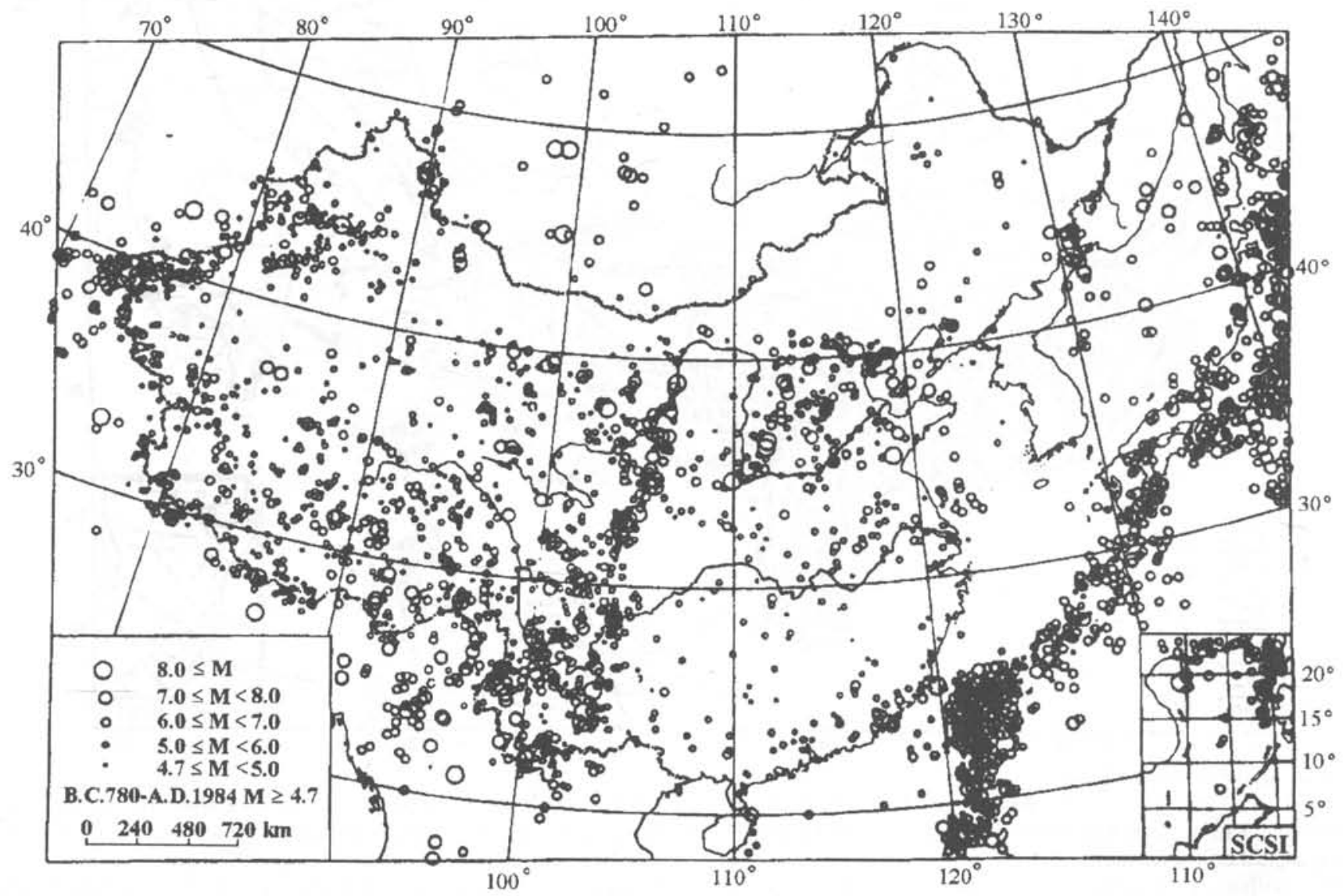

Figure 1 Epicenter distribution of Ms $\geq 4.7$ earthquakes in China and adjacent areas. 
of high seismicity alternating with low seismicity. For instance, according to the historical records in North China where the data are believed to be complete after the year 1400, four active seismicity periods can be recognized, in which $M \geq 6$ earthquakes occurred densely. Each period lasts about 300 years with active episode followed by a quiescent one. Within the $3 \mathrm{rd}$ and 4 th periods, several seismic episodes can be further recognized, according to the degree of clustering of $\mathrm{M} \geq 4.7$ earthquake occurrence. Each episode, including seismic clustering phases and quiet phases, lasted about 20-30 years.

The episodic phenomena of seismicity in eastern China can be compared with the cases in the region from Japan to Korea or even larger. In a seismic episode, earthquakes often concentrate in a certain seismotectonic belt, which is regarded as the main active belt (region) of this episode (Fu Zhengxiang et al., 1990). This phenomenon has been obviously showed by the four active episodes in China since 1900.

\section{Tectonic framework of large earthquakes}

China continent is one of the regions with frequent $M \geq 8$ earthquakes in the world. Fourteen such earthquakes have occurred since this century, which occupy $28 \%$ of that in the global continents. The places where these large earthquakes occurred are characterized by major geological structures with the strongest neotectonic deformation in the continent. The contrast between the uplift of the Tibetan plateau and the subsidence of the North China plain approaches 20 $\mathrm{km}$ during the Cenozoic Era. The width of deformation region caused by collision and subduction is as wide as $2000-3000 \mathrm{~km}$. The lithosphere is extremely heterogeneous with changing crustal thickness, and developing low speed layers and high conductivity layers . All these characteristics provide the essential conditions for large earthquakes to occur in these regions (Ma Xinyuan et al., 1987).

In North China, large earthquakes often occured along the edges of Cenozoic rift basins or in their interiors. These basins are grabens or half grabens, where a series of listric normal faults are often present. These faults merge downward into the basal detachments at the depth of 10-17 km. Most of these listric faults do not related to large earthquakes. On one side of these deep faults often exist low speed and high conductivity bodies and detachments (Liu Guodong et al., 1996).

Based on deep seismic reflection profiles and data of other geophysical surveys, following results on the tectonic framework of some area with large earthquakes in North China have been found (Wang Chunyong, 1996):

1) In North China, seismogenic structures often consist of moderate-low angle normal faults in the upper crust, high-angle faults in the mid-lower crust, and detachments in the middle crust. The junction of the three faults favors the stress concentration and energy accumulation .

2) The high-angle faults in the mid-lower crust can be thought as the seismogenic faults of large earthquakes. These faults might exist before Cenozoic extension, and was reactivated recently. Shear stress acts on the faults to cause dextral slip, whereas the detachment may play an important role in the tectonics of Cenozoic extension basin.

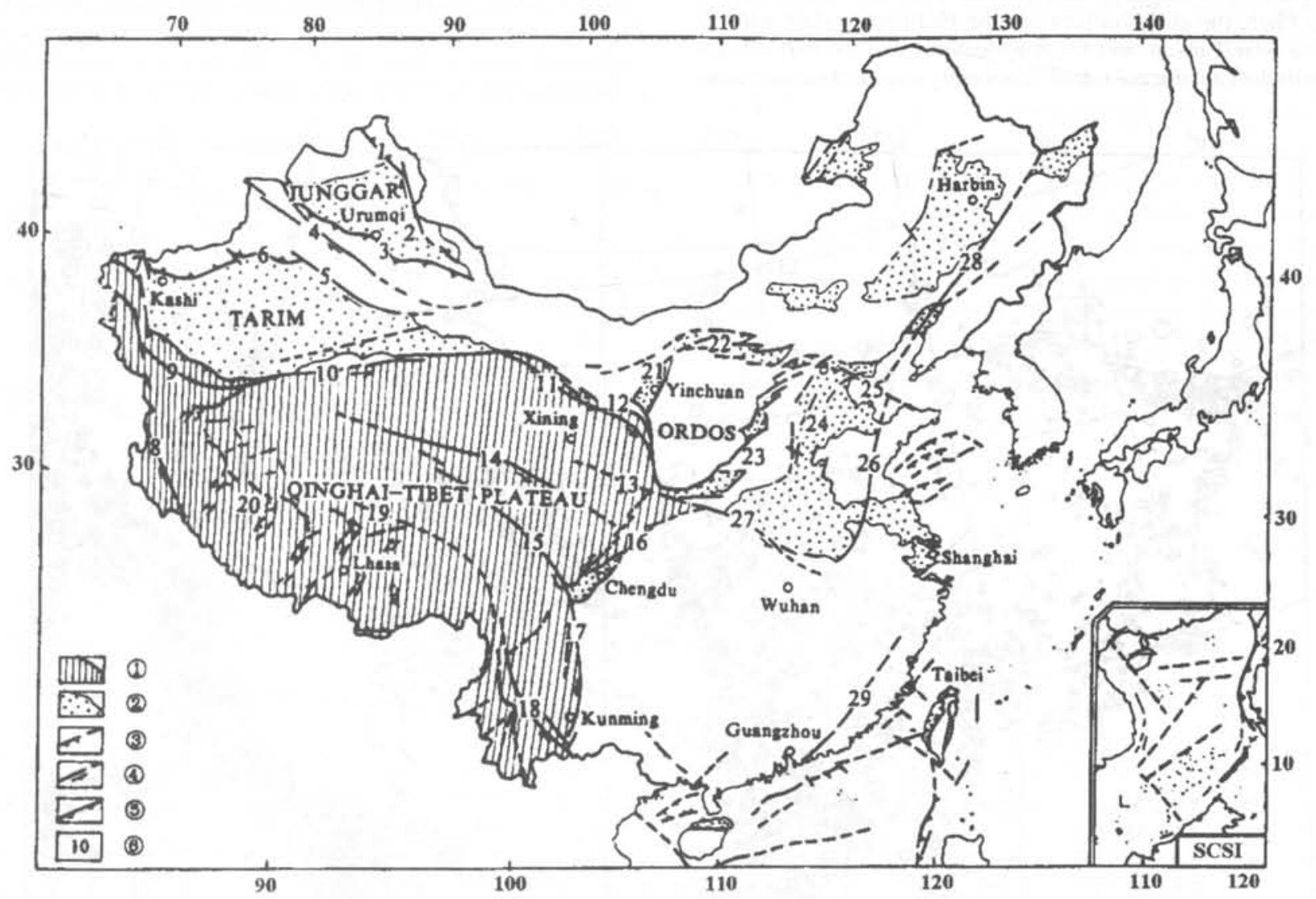

Figure 2 Active faults in China

(1) Qinghai-Tibet plateau; (2) Basin; (3) Normal fault; (4) Strike-slip fault; (5) Thrust fault; (6) Number of active fault. 1.Altai fault; 2.Ertai fault; 3.Northern piedmont fault of Tianshan; 4. Borohoro fault; 5 . Kuluktag fault; 6 .Southern piedmont fault of Tianshan; 7.Kazikeaete fault; 8.Karakorum fault; 9.Kangxiwar fault; 10.Altun fault; 11.Qilian fault; 12.Haiyuan fault; 13.Northern piedmont fault of western Qinliang; 14.Kunlun fault; 15.Xianshuihe fault; 16.Longmenshan fault; 17.Xiaojiang fault; 18.Red river fault; 19.Jiali-Bengco fault; 20.Normal faults of southern Tibet 21.Helanshan piedmont fault; 22.Hetao faults; 23. Fenwei faults; 24.Hebei plain faults; 25.ChangpingFengnan fault 26.Tanlu fault; 27.Danfeng fault; 28. Yilan-Yitung fault; 29. Changshao fault; 30.Longitudinal valley fault of Taiwan. 
Large earthquakes usually occurr in the transitional zones between the bottoms of major listric faults and tops of buried deepfaults with high angles. Similar cases were found at the sites of Xintai and Linfen. So we suggest that large earthquakes in North China are related to rupture of deep faults in the mid-lower crust, the decoupling among different crustal layers, and the block rotations caused by decoupling. All these actions are result of the disintegration of craton, the rift zones of which provide a prerequisite for large earthquake generation.

In western China, large earthquakes ( $M \geq 8)$ mostly occur along three seismic zones that form a triangle shape; the Himalayan seismic belt, the North-South seismic belt, and the central Asia (the Tianshan) seismic belt. North-dipping thrust faulting earthquakes often occur along the Himalayan seismic belt as a result of southward thrusts of the Tibetan plateau onto Indian subcontinent. Within the Tibetan plateau, normal-faulting earthquakes indicate east-west extension as the ongoing current tectonic processes. Within the North-South seismic zone, occurences of earthquakes are usually controlled by large strike-slip faults such as the Xianshuihe fault and the Xiaojiang fault. Reverse faulting and folding are predominant tectonic processes in the central Asia seismic belt (Tapponnier et al., 1991; Zhang Peizhen et al., 1994). Earthquakes in western China can be correlated with surface geological structures such as active faults and folds. The slip rates of these faults are usually several to tens millimeters per year. The recurrence intervals of $M^{\circ} \geq 8$ earthquakes are much shorter than those in eastern China. According to statistical results for 51 rupture events (including paleoearthquakes) on ten active faults, average recurrence intervals are about 2000 years, whereas in eastern China the intervals are over 3500 years even 5000 years or more (Ding Guoyu, 1991).

It appeared that large earthquakes in western China are caused by the compression and rotations between the lithospheric terrains and tectonic blocks. Except the extensional rift type earthquakes caused by the compression in southern Tibet, the seismotectonic pattern that produces large earthquake in eastern China is seldom observed in western China.

\section{Active faults}

In China, active faults are generally defined as those which have been active during Quaternary and are likely to be active in the future. In engineering stabilization evaluation, active faults are defined to be those showing slip during the late Pleistocene. There are many active faults in China continent. Because of their close relation with seismicity in recent years, detailed mapping $(1: 50,000)$ and comprehensive studies have been conducted on the major active faults such as the Altun faults, the Qilian front fault, the Kunlun front fault, the Honghe fault, and the Xianshuihe fault in and around the Tibetan plateau, the Ertai fault and the North Tianshan front fault in Xinjiang province, the faults around the Ordos Block, and the Tanlu fault in Shandong province, etc. According to a large number of offsets on these faults and related chronological data, a vast amount of data have been obtained on the geometry, behavior, segmentation, seismicity, slip rates and accumulated displacement along these active faults. Figure 2 shows the distribution of main active faults in China.

The slip rates of active faults within a tectonic block are 1-2 order smaller than those along the main active faults that bound the blocks. The horizontal slip rates of these main active block-bounding faults west of the "N-S seismic zone", are generally $3-15 \mathrm{~mm} / \mathrm{a}$, and those within the blocks are usually $1-3 \mathrm{~mm} / \mathrm{a}$ or even smaller. In eastern China, rates along block-bounding faults are about 1-4 $\mathrm{mm} / \mathrm{a}$, and $0.5-1 \mathrm{~mm} / \mathrm{a}$ within the blocks. These patterns are essentially similar to the spatial distribution of seismicity (Ding Guoyu, 1986).

It is very important to estimate the total amount of displacement and slip rates of major active faults in order to understand the characteristics of fault activity and seismic hazards. During the last decades, a large amount of data have been accumulated from detailed investigations along many active faults of China. Based on the data of offset of geomorphic units, geologic units and paleomagnetic data, etc., the amount of accumulated displacements of these

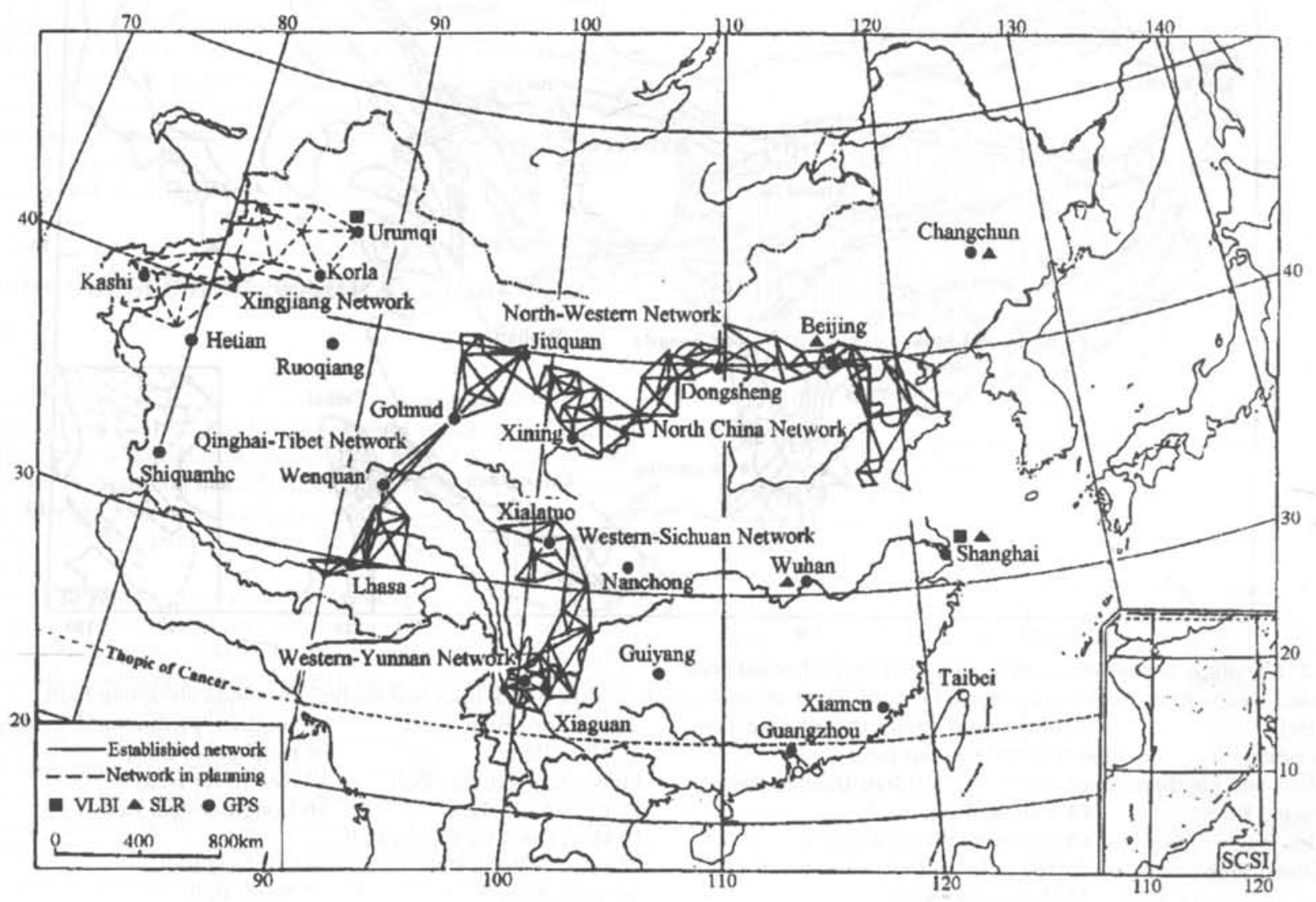

Figure 3 The GPS crustal monitoring networks along active zones in China (from Seismological Institute, SSB) 
active faults or boundaries can be estimated as follows: about 200-300 km since Oligocene, 70-80 km since late Miocene or early Pliocene and $10-20 \mathrm{~km}$ in the last $1.2-1.6 \mathrm{Ma}$ BP respectively. The average rate of these active faults is about $1-8 \mathrm{~mm} / \mathrm{a}$ in western China, and $0.2 \mathrm{~mm} / \mathrm{a}$ in North China.

The places with greatest amount of accumulated displacements were located at the margins of Qinghai-Tibet plateau, and at the eastern and western tips of the Himalayan belt. The seismic activity is strongest in Eastern Asian Continent.

Active faults mark the main active boundaries of the intracontinental subplates or neotectonic blocks in Chinese continent. More than 30 main active block-bounding faults can be identified, $80 \%$ of which are convergent or strike slip faults, and the other $20 \%$ are divergent or strike slip-divergent ones. This indicates that the Chinese continent is chiefly in the dynamic environment of compression and rotational shear. Fault plane solution of earthquakes shows the similar results.

\section{Recent crust movement}

Earthquake is a product of fault displacement. Seismic potential either in a region or along a fault is closely related to the recent crustal deformation.

During last twenty years, geodetic survey across main active faults in China has been carried out by the Geodetic Brigade of State
Seismological Bureau (SSB). Data on crustal deformation have been obtained. On the basis of those data a map of recent vertical crustal deformation of China has been compiled. This map represents data of the repeated precisely leveling from the National Surveying and Mapping Bureau (NSMB), State Seismological Bureau (SSB) and others during a 30 -year interval, including 564 level marks, 235 level routines which are $90,000 \mathrm{~km}$ long, and $204,000 \mathrm{~km}$ resurveying routines in all, covering the whole Chinese mainland. The results indicate that recent crustal deformation is obviously controlled by regional tectonics. It reflects the latest activity of major crustal block movement and active faulting (Ying Shaofen et al., 1996).

Preliminary progress has also been made by using space techniques in recent years. An important project "Recent Crustal Motion and Dynamics in China (RCMDC)" started in 1991, which is an interdisciplinary project of astronomy, geodesy, geophysics, and geology. The main attendees are the Chinese Academy of Sciences, State Seismological Bureau, National Surveying and Mapping Bureau, and Survey Bureau of the Central Military Commission. The VLBI stations have been built in Shanghai and Urumqi. The relative motion between the Shanghai VLBI station and the Alaska, Hawaii, Kashima in Japan, and Australian stations has been obtained based on the VLBI data from international joint measurement during 1988-1992. The relative shortening rate is $27.3 \mathrm{~mm} / \mathrm{a}$ between Shanghai and Japanese Kashima station, and $59.2 \mathrm{~mm} / \mathrm{a}$ between Shanghai and Australian DSS45 station respectively. The SLR networks were set up in Shanghai, Wuhan, Changchun, and Beijing. The repeated GPS observation has already been conducted along the

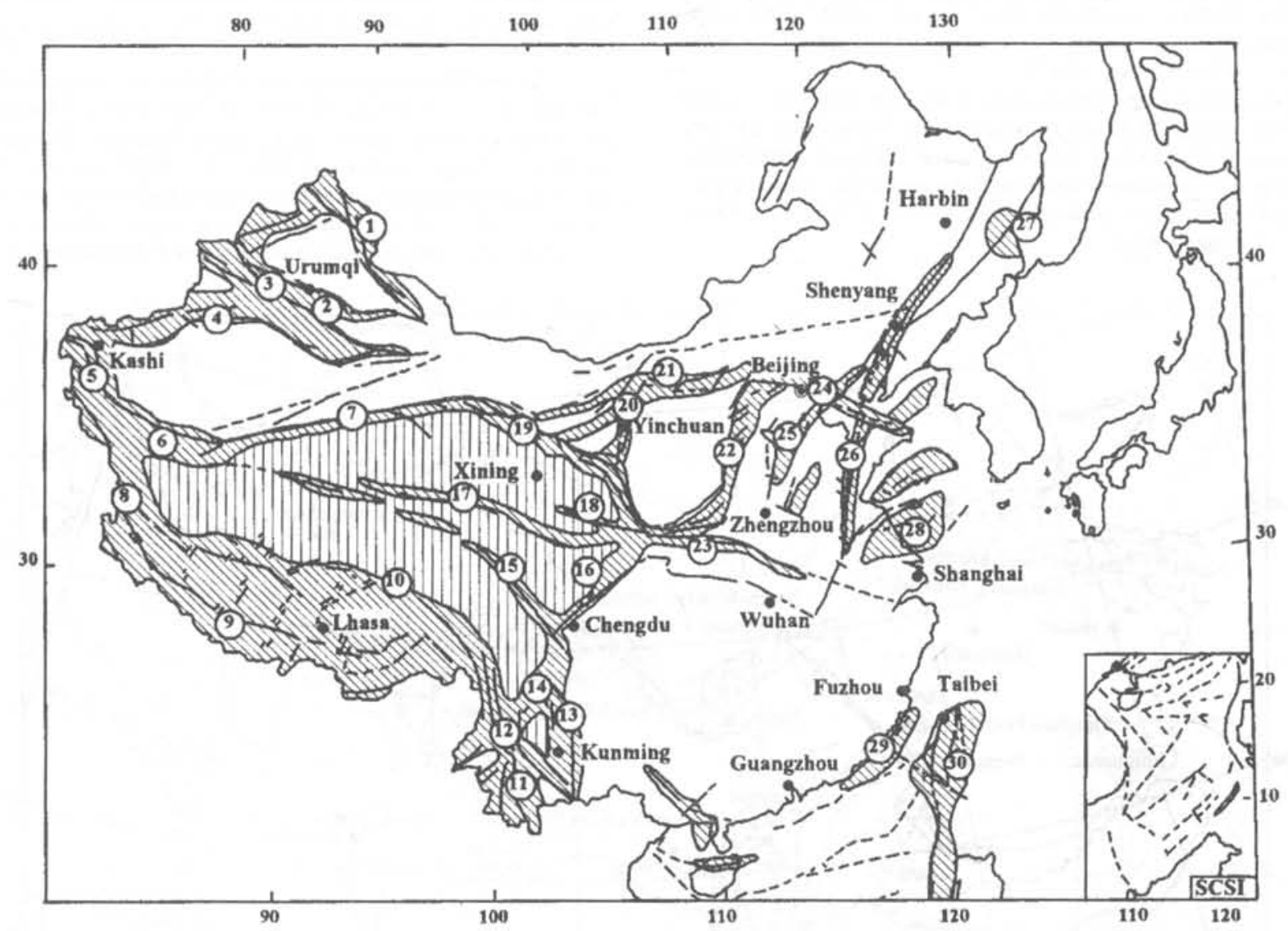

Figure 4 The main seismotetonic belts in China and adjacent area

The shaded area with vertical lines indicate Qinghai-Tibet seismotectonic region. Thick lines and dashed lines indicate active fault.

1 Altai Belt; $\quad 2$ Northern piedmont Belt of Tianshan;

5 Pamir Belt; 6 Western Kunlun Belt:

9 Himalaya and Southern Tibet Belt;

13 Xiaojiang Belt;

17 Kunlun Belt;

14 Yunnan Belt;

20 Yinchuan Belt;

18 Western Qinling Belt;

21 Hetao basin Belt:

24 Zhangjiako-Behai Belt; 25 Hebei plain Belt;

28 Southern Huanghai Sea Belt;
3 Borohoro Belt;

7 Altun Belt;

11 Western Yunnan Belt;

15 Xianshuihe Belt;

19 Hexi Corridor-Qilian Belt;

22 Fenwei Basin Belt; 23 Danfeng Belt;

26 Tanlu Belt;

29 South-east Coast Belt;
4 Southern piedmont of Tianshan;

8 Karakorum Belt;

12 Red River Belt;

16 Longmenshan Belt;

27 Yanji Belt;

30 Taiwan Belt. 
active seismic belts in western Yunnan, the Hexi Corridor region, the Tibetan plateau, Beijing and Tianjin (Figure 3).

It has always been a noticeable subject to measure the continental convergence rate between the Eurasian and Indian plates and the status of its effects on the continent of China to the north and east. The repeated GPS observation in 9 sites on the Tibetan plateau and its adjacent area were made by the Institute of Seismology, State Seismological Bureau from 1991 to 1996. The data showed that the $\mathrm{N}-\mathrm{S}$ shorting rate was 7-12 mm/yr. within the southeastern part of Tibetan Plateau, and the southeastward slip rate of the Sichuan-Yunnan block was about $10-16 \mathrm{~mm} / \mathrm{yr}$.

Seven baseline vectors and their rates were accurately calculated by Zhu Wenyao et al. based on the twice measurements among Lhasa, Wenquan, Golmud, Xialatuo, Xining and Xiaguan GPS stations in Tibet and its adjacent area in 1992 and 1994.

In addition, twice GPS baseline measurements in the western part of Yunnan province were carried out by the Institute of Seismology, SSB, and Hannover University of Germany in 1988 and 1991 (Lai Xian et al., 1994). Forty eight base lines were observed in 1988 , and twenty five in 1991. The inversion of fault displacement based on these data shows that the dextral slip occurred in about 268 $\mathrm{km}$ long segment of Jianchuan-Lijiang fault zone and Honghe fault, and the rapid strain accumulation occurred in the central segment of Jianchuan-Lijiang fault zone. Based on this study, they predicted that an earthquake would occurred in this region. An earthquake with Ms=7.0 occurred in this region on 3 February, 1996 soon afterwards.

A GPS network including 42 stations was set up along the main active tectonic zones by the First Land Deformation Monitoring Center, SSB in order to monitor earthquakes and the state of recent crustal deformation in North China around Beijing and Tianjin. The longest side of the network is $362 \mathrm{~km}$, and the shortest is $30 \mathrm{~km}$. The network is more than $1400 \mathrm{~km}$ long in E-W, and $400 \mathrm{~km}$ (the western part) $-800 \mathrm{~km}$ (the eastern part) wide. It covers the Hetao basin, basins in northern Shanxi and Tanlu fault zone et al. with a total area of $70,000 \mathrm{~km}^{2}$ (Li Yanxing, 1993).

As stated above, the space technology such as VLBI, SLR, GPS, and high-precision gravimetry has made great progress not only in equipment but also in research by many departments in China during the last decades. Now, a project "Crustal Movement Observation Network of China" is prepared to be launched. All these works provide an important basis to obtaining high-precision data on recent crustal motion and to facilitate the understanding of the seismic activity and seismotectonics of China.

\section{Division of seismotectonic regions and belts}

The China continent consists of several geological terrains, relative rigid blocks, and relative ductile belts, each of which has a long history of geological evolution. Together, they form a complex geological pattern. Recognition of each terrain evolution of recent tectonic activity of each block and dividing seismotectonic regions and belts form important basis for assessing its future earthquake potential (Figure 4).

Based on the characteristics of tectonics and seismicity, we can divide the China continent and the neighbouring region into eight seismotectonic regions, which are the Qinghai-Tibet Plateau, the Xinjiang, the Heilongjiang, the North China, the South China, the Indo-China, the Taiwan, and the South China Sea regions. Each of these regions is bounded by major active faults. The historical earthquakes and many paleoearthquakes are mainly distributed along these active faults. The strong earthquakes with magnitude about 8 are only distributed in the western part of the Xinjiang Region (from the Pamir to the Altai), the margin of the Qinghai-Tibet plateau, the North China Region (around the Ordos, the Tanlu fault), and the Tai- wan Region. The other regions and areas are the places of smaller and medium sized earthquakes.

The seismotectonic regions can be further divided into many seismotectonic belts. These seimotetonics belts reflect the regional differences of tectonics and seismic activities (Gao Weiming,1991). 30 seismotectonic belts have been divided in which tectonic movement and seismic activity share the common tectonic attributes. Active faults are the major structures of seismotectonic belts.

The division of seismotectonic regions and belts provides an important background and regional framework for further research on earthquake prediction and seismic hazard evaluation.

\section{References}

Centre for Analysis and Prediction, State Seismological Bureau, 1990, Map of Seismicity in China $(1: 6,000,000)$, China Cartographic Publishing House, Beijing (in Chinese with English notes).

Ding Guoyu, 1986. A preliminary disussion on the status of recent intraplate motions in China: Kexue Tongbao, 33(1): 52-57.

Ding Guoyu, 1991, The inhomogeneity of Holocene faulting: Earthquake Research in China, 5(2).

Fu Zhengxiang et al., 1990, Spatial heterogeneity of strong earthquake activities in East China mainland and its implications of earthquakes mechanics: Earthquake Research in China, 6(4).

Gao Weiming, 1991. Map of Active Tectonics in China and Its Adjacent Areas, Seismological Press, Beijing, China (in Chinese with English notes).

Gu Gongxu (editor in chief),1989. Catalogue of Chinese Earthquakes (1831 BC-1969 AD), Science Press, Beijing.

Lai Xian, Xing, C., Seeber, G., Torge, V., Chao, D. and Zhao, S., 1994. Crustal movement characteristics research in Yunnan, China. - GPS Campaigns in 1988 and 1991: Proceeding of the $\mathrm{CRCM}^{\circ} 93$, Kobe, 1993. 321-324.

Li Yanxing, 1993, The establishment of the GPS monitoring network in North China: Dynamic Geodesy, 9(4), 36-45.(in Chinese)

Liu Guodong et al., 1996. A study on seismogenic structure and earthquake generating indication of large earthquakes, North China: Earthquake Sciences, 12(3):53-58, (in Chinese).

Ma Xingyuan et al., 1987, An outline of the lithospheric dynamics of China, Geological Publishing House, Beijing.

Mogi, K., 1985, Earthquake prediction. Academic Press, Tokyo, 355p.

Sun Fuping, and Zhao Ming, 1994. Study of Plate motion and crustal deformation from satellite laser ranging site vidocitico: Acta Geophysica Sinica, 37(5)

Tapponnier, P., Meyer, B. Avouac, J. P.. Peltzer, G., Gaudemer,Y,. Shunmin, G., Hongfa, X., Delun, Y., Zhitai, C., Shuahua, C. and Huagang, D. 1991. Active thrusting and folding in the Qilianshan, and decoupling between upper crust and mantle in Northeastern Tibet: Earth Planet. Sci. Lett., 97, 382-403.

Wang Chunyong, 1996, Deep seismic reflection profiling in the strong earthquake areas of the North China, in "Achivements of seismic hazard prevention and reduction in China", Seismological Press, Beijing, 48-71.

Ying Shaofen et al., 1996, The characteristics of the Chinese continental deformation and the seismic hazards zoning: Dynamic Geodesy, 12(1), 211 (in Chinese).

Zhang Peizhen, Deng Qidong, Xu Xiwei, Peng Shizhen, Yang Xiaoping, Feng Xangyue, and Li Jun, 1994, Blind thrust, folding earthquake and the 1906 Manas earthquake, Xinjiang: Seismology and Geology, 16(3), 193 204 (in Chinese).

Ding Guoyu was born in 1931, graduated in 1952 from the Geological Department of Peking University. He is research professor at the Centre for Analysis and Prediction, State Seismological Bureau (SSB), Chairman of the Science and Technology Committee of SSB and Academician of the Chinese Academy of Sciences. His research area is neotectonics, active tectonics and seismotectonics.

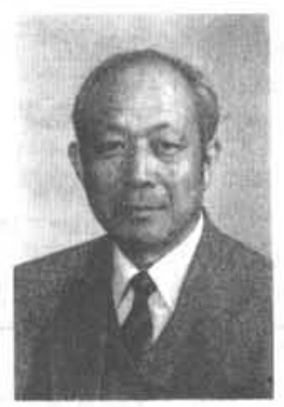

